\title{
An Evaluation of Different Risk Ranking Systems
}

\author{
Huimei Sha, Ron J. Thiessen, Gopal Achari* \\ Department of Civil Engineering, University of Calgary, Calgary, Canada. \\ Email: "gachari@ucalgary.ca \\ Received May $28^{\text {th }}, 2013$; revised July $3^{\text {rd }}, 2013$; accepted August $8^{\text {th }}, 2013$ \\ Copyright (C) 2013 Huimei Sha et al. This is an open access article distributed under the Creative Commons Attribution License, \\ which permits unrestricted use, distribution, and reproduction in any medium, provided the original work is properly cited.
}

\begin{abstract}
A number of risk ranking systems for contaminated sites have been developed by different jurisdictions. While the intent of each of these systems is similar, it is not clear whether they provide results that are comparable. In this paper, 20 contaminated sites are used to assess the United States' Preliminary Assessment (PA) system, Sweden's Methods for Inventories of Contaminated Sites (MICS) and New Zealand's Risk Screening System (RSS) methods. The results were compared with each other and with Canada's National Classification System for Contaminated Sites (NCSCS) as well as preliminary quantitative risk assessment (PQRA) results. The objectives were to determine if the systems yield similar recommendations regarding further actions, and to assess if there are acceptable correlations between different methods. The study concludes that PA, MICS and NCSCS methods can achieve similar conclusions, although there is a certain degree of inconsistency that is present, RSS can distinguish the very high and very low risk sites and, acceptable correlations exists among the methods except for PA and PQRA.
\end{abstract}

Keywords: Risk Ranking System; Contaminated Sites; Risk Assessment; PA; MICS; RSS; NCSCS and PQRA

\section{Introduction}

A contaminated site is one in which soils, sediments and water (ground and surface) are contaminated by substances above benchmark criteria. There is a potential for such sites to pose threat to human health and/or the environment. Contaminated sites management refers to the process of identifying, assessing and remediating contaminated sites in order to protect soil and water resources [1].

The number and extent of problems associated with contaminated sites are so significant that many countries and jurisdictions have developed strategies to tackle these sites, including legislative measures, assessment procedures, remediation, and funding [2]. Risk screening systems are tools that have been developed to prioritize contaminated sites for further actions. The intent is to have a consistent and scientifically defensible system to rank or categorize sites so that resources can be allocated for either risk management or remediation. Preliminary Assessment (PA) in United States, Methods for Inventories of Contaminated Sites (MICS) in Sweden, Risk Screening System (RSS) in New Zealand and National Classification System for Contaminated Sites (NCSCS) in Canada are all used as risk screening tools.

${ }^{*}$ Corresponding author.
In previous research by Thiessen and Achari [3], the 2008 NCSCS was evaluated against preliminary quantitative risk assessment (PQRA) results. The current paper extends the previous work by Thiessen and Achari [3] to investigate three other risk ranking systems and evaluate their output against each other as well as with PQRA results. To this end, data from 20 actual contaminated sites are used. First, the results from the three methods (PA, MICS and RSS) are compared with each other and with the results of the Canadian 2008 NCSCS and PQRA, to assess if the four risk ranking systems will achieve similar results regarding further action recommendations. Second, Spearman rank correlations statistics are applied to determine if acceptable correlations exist between the results of the three methods, NCSCS and PQRA results.

\section{Background of Different Risk Ranking Systems}

\subsection{US's Preliminary Assessment}

The US EPA developed the Hazard Ranking System (HRS) to evaluate sites for eligibilities on the National Priorities List (NPL). It is further used to prioritize those sites that pose serious risks to public health or the environment, and are eligible for Superfund-financed reme- 
dial action. Preliminary Assessment (PA) provides the initial step to differentiate those sites that are eligible for further investigation from sites that pose little or no risks to human health and the environment [4]. Preliminary Assessment (PA) is a limited-scope investigation in which assessors use readily available information to develop scores for each pathway. The PA site scores are obtained by combining the four pathway scores using a rootmean-square equation [4].

\subsection{Sweden's MICS}

Methods for Inventories of Contaminated Sites (MICS) are used to prioritize between contaminated sites in Sweden to select those to be investigated more thoroughly. This method permits a comprehensive assessment by considering four components: hazard level assessment, contamination level assessment, migration potential and sensitivity/protection value. MICS can also be used in cases where data are limited [5].

\subsection{New Zealand's RSS}

Risk Screening System (RSS) is a simplified version of New Zealand's Ministry for the Environment's Rapid Hazard Assessment System (RHAS), published in 1993. RHAS is based on the Canadian National Classification System for Contaminated Sites published in 1992. The Risk Screening System (RSS) is based on a risk equation which is made up of three components: hazard, exposure pathway and receptors [6].

\subsection{Canada's NCSCS}

The Canadian National Classification System for Contaminated Sites (NCSCS) is a method for evaluating contaminated sites according to their current or potential adverse impact on human health and the environment. It assigns sites to one of four classes: Class 1-High Priority for Action (Total Score > 70), Class 2-Medium Priority for Action (Total Score 50 - 69.9), Class 3-Low Priority for Action (Total Score 37 - 49.9), Class N-Not a Priority for Action (Total Score < 37) [7]. The background, stages of development, characteristics and scoring processes of NCSCS are detailed by Thiessen [8].

\subsection{Background of PQRA}

The preliminary quantitative risk assessment (PQRA) system is made up with two parts, human health risk assessment and ecological risk assessment (ERA). Health Canada describes a preliminary quantitative risk assessment in the context of human receptors [9]; and CCME [10] describes a preliminary quantitative ecological risk assessment (ERA) as a tier 2 risk assessment, which is in-between a screening ERA and a detailed quantitative
ERA. In the human health risk assessment of PQRA, the maximum on-site concentration of each contaminant is employed to quantify risks posed to site receptors making it a conservative method. The preliminary quantitative ERA of PQRA is based on a combination of measured site-specific data and previously compiled information [10].

The preliminary quantitative risk assessments (PQRA) has been chosen as the screening level risk assessment protocol to evaluate the performance of the risk ranking systems and has the ability to determine the site priority based on assessment of primarily existing information, and to address both risks to human health and the ecological environment [3]. Thiessen and Achari [3] summed hazard quotients across exposure routes for a receptor to obtain the hazard quotient across all cells and all contaminants to characterize receptor risk. In this research the maximum hazard quotients are used to compare the three methods being evaluated. A hazard quotient does not necessarily convey a likelihood effect upon human and ecologic receptors, but it represents the potential of adverse effect, the higher the hazard quotient is, the higher the adverse effect will be.

\section{Data Collection and Methodology}

\subsection{Sites Selection}

Data from twenty actual contaminated sites from different jurisdictions and with different contaminants and their levels were used in this research. The sites and their details are provided in Table 1. The sites were selected from the Canadian Federal Contaminated Site Inventory [11].

\subsection{Project Assumptions}

Like in any two systems, that have different criteria and methodologies, there are some assumptions that are worth mentioning. These include:

1) The contaminated sites are considered suitable to be evaluated by all three methods even though the pollutants in each site may not be suitable for such. For example, site 8 is a site contaminated by salts, which is not eligible for The Comprehensive Environmental Response, Compensation, and Liability Act (CERCLA) response. Nonetheless, it is still used and is a good example demonstrating that PA method emphasizes more on the surface water pathway.

2) The CERCLA petroleum exclusion is not applicable here.

3) According to US's PA method, a site with a PA score of 28.50 or greater is eligible for further superfund processes, a site with an PA score less than 28.50 should 
Table 1. Selected contaminated sites [8].

\begin{tabular}{|c|c|c|c|c|}
\hline Site ID & Contaminant Source & Province (Territory) & Ecoregion & Contaminants \\
\hline 1 & Waste soil landfill & $\mathrm{BC}$ & Eastern Vancouver Island & Metals, PCBs, PAHs, PHCs \\
\hline 2 & Above ground storage tank & $\mathrm{BC}$ & Western Vancouver Island & PAHs, PHCs \\
\hline 3 & Weathered paint & ON & Manitoulin-Lake Simcoe & Metals \\
\hline 4 & Mechanical repair area & $\mathrm{BC}$ & Coastal Gap & Metals, PAHs, PHCs \\
\hline 5 & Above ground storage tank & YT & Ruby Ranges & PAHs, PHCs \\
\hline 6 & Waste dump & $\mathrm{BC}$ & Eastern Vancouver Island & Metals, PAHs, PCBs, PHCs \\
\hline 7 & Soak away pit & $\mathrm{ON}$ & St. Lauren Lowlands & $\mathrm{CHCs}$ \\
\hline 8 & Salt storage area & $\mathrm{AB}$ & Northern Continental Divide & Salts \\
\hline 9 & Underground storage tank & PE & Prince Edward Island & Metals, PAHs, PHCs \\
\hline 10 & Spilled fuel & NB & Maritime Lowlands & Metals, PAHs, PHCs \\
\hline 11 & Chemical dump & $\mathrm{ON}$ & St. Laurent Lowlands & CHCs, Metals, PHCs \\
\hline 12 & Underground storage tank & $\mathrm{ON}$ & Thunder Bay-Quetico & PHCs \\
\hline 13 & Above ground storage tank & MB & Aspen Parkland & PHCs \\
\hline 14 & Underground storage tank & SK & Aspen Parkland & PHCs \\
\hline 15 & Wastewater lagoon & SK & Aspen Parkland & PHCs \\
\hline 16 & Pesticide dump & SK & Aspen Parkland & Metals, Phenols \\
\hline 17 & Equipment dump & NU & Eureka Hills & Metals \\
\hline 18 & Above ground storage tank & NT & Tazin Lake Upland & PHCs \\
\hline 19 & Waste dump & $\mathrm{AB}$ & Fescue Grassland & DDT, Metals, PAHs \\
\hline 20 & Above ground storage tank nest & NT & Tuktoyaktuk Coastal Plain & PHCs \\
\hline
\end{tabular}

receive a "no further remedial action planned" (NFRAP) recommendation. For the sake of this comparison, all site scores are calculated and considered.

4) According to MICS, only contaminated sites that have high levels of contamination and those that are hazardous should go forward with comprehensive risk assessment. But in this research, risk assessments are carried out on all sites, irrespective.

\subsection{PA Scoring Processes}

The PA site score for each site was determined by using PA score sheets and guidance provided by US EPA [4]. Table 2 provides the pathway scores and the combined PA score for the different sites. The PA score ranges from 0 to 100 , and is obtained by combining the four pathway scores, expressed in Equation (1), using the following root-mean-square equation:

Site score:

$$
S=\sqrt{\frac{\left(\mathrm{S}_{\mathrm{gw}}\right)^{2}+\left(\mathrm{S}_{\mathrm{sw}}\right)^{2}+\left(\mathrm{S}_{\mathrm{s}}\right)^{2}+\left(\mathrm{S}_{\mathrm{a}}\right)^{2}}{4}}
$$

where $\mathrm{S}_{\mathrm{gw}}$ : ground water migration pathway score;

$\mathrm{S}_{\mathrm{sw}}$ : surface water migration pathway score;

$\mathrm{S}_{\mathrm{s}}$ : soil exposure pathway score;

$\mathrm{S}_{\mathrm{a}}$ : air migration pathway score.

Each PA pathway score, expressed in Equation (2), is the product of the three factor category values (likelihood of release or likelihood of exposure, waste characteristics, and targets) divided by a scaling factor and then normalized to 100 points.

Pathway score:

$$
A=\frac{\mathrm{LR}^{*} \mathrm{WC} * \mathrm{~T}}{82,500}
$$

where: LR: likelihood of release; WC: waste characteristic; $\mathrm{T}=$ targets factor.

\subsection{MICS Scoring Processes}

MICS risk ranking is determined using four factors: hazard assessment, contamination level, migration potential and sensitivity/protection value [5]. Each of these factors is assigned between one and four levels according to site 
Table 2. Exposure pathway and PA scores.

\begin{tabular}{|c|c|c|c|c|c|c|}
\hline Sites & $\mathrm{Gw}$ & $\mathrm{Sw}$ & Soil & Air & PA scores & Action Recommendations \\
\hline 1 & 34.8 & 100 & 8.5 & 1.8 & 53.1 & Further Action Needed \\
\hline 2 & 0.6 & 0 & 5.2 & 16.2 & 8.5 & No Action Needed \\
\hline 3 & 0.6 & 28.4 & 0 & 3.0 & 14.3 & No Action Needed \\
\hline 4 & 0.6 & 65.1 & 1.2 & 13.9 & 33.3 & Further Action Needed \\
\hline 5 & 4.1 & 23.4 & 26.2 & 43.8 & 28.1 & No Action Needed \\
\hline 6 & 54.4 & 70.4 & 8.5 & 26.2 & 46.6 & Further Action Needed \\
\hline 7 & 0.6 & 12.7 & 0 & 16.7 & 10.5 & No Action Needed \\
\hline 8 & 0.6 & 28.8 & 3.6 & 0.8 & 14.5 & No Action Needed \\
\hline 9 & 0.6 & 65.1 & 2.2 & 3.6 & 32.6 & Further Action Needed \\
\hline 10 & 11.3 & 61.1 & 1.6 & 11.9 & 31.6 & Further Action Needed \\
\hline 11 & 1.4 & 25.8 & 2.2 & 3.2 & 13.1 & No Action Needed \\
\hline 12 & 0.6 & 2.1 & 0 & 0.5 & 1.1 & No Action Needed \\
\hline 13 & 37.3 & 0.6 & 19.2 & 33.1 & 26.7 & No Action Needed \\
\hline 14 & 2.4 & 0.5 & 2.2 & 3.1 & 2.3 & No Action Needed \\
\hline 15 & 2.4 & 0.5 & 0 & 3.1 & 2.0 & No Action Needed \\
\hline 16 & 2.4 & 0.5 & 1.2 & 0.8 & 1.4 & No Action Needed \\
\hline 17 & 0.5 & 0.5 & 1.6 & 3.2 & 1.8 & No Action Needed \\
\hline 18 & 0.5 & 0 & 2.2 & 3.2 & 2.0 & No Action Needed \\
\hline 19 & 38.0 & 69.8 & 13.2 & 4.4 & 40.3 & Further Action Needed \\
\hline 20 & 0.6 & 4.6 & 0 & 3.2 & 2.8 & No Action Needed \\
\hline
\end{tabular}

conditions. Finally, the four aspects are weighed together into an overall assessment value using a schematic diagram. One of our risk classes is assigned to the site being assessed. They are Very high risk (Class 1), High risk (Class 2), Moderate risk (Class 3), Low risk (Class 4). The sites with high or very high risk levels are recommended for further investigations. Figure 1 is an example of acomprehensive risk assessment on a schematic diagram. The schematic diagram used in the comprehensive assessment includes four horizontal lines; the risk class is determined by the positions of various points in the schematic diagram. If all points on all lines fall within the same class range, the site is assigned to that class; but when the points are scattered among two or more risk classes, the assessor uses professional judgment to decide which class best describes the site. The size of the site and the number of different contaminants present on site should be considered when making the decision. If the site is larger and has a greater number of contaminants, the risk is considered to be greater. The MICS site risk ranking for each site is provided in Table 3.

\subsection{RSS Scoring Processes}

The RSS risk ranking for each site (Table 4) was determined by using the template and guidance provided by MENZ [6]. The Risk Screening System (RSS) is based on a risk equation made up of three components: hazard, exposure pathway and receptor. The presence of all three components means there is some level of risk, while the absence of any of the components means there is no risk. The final result of RSS is taken as the worst-case risk rank among the three pathways. Even if only one pathway posed a significant risk by a contaminated site, the site risk rank will be determined by this exposure pathway. There are two operation modes in this method, the standard mode and the special case mode; the standard mode is used in this research as it allows comparison between dissimilar sites.

\subsection{Comparison between the Four Risk Ranking Systems}

The results of the four risk ranking systems are compared and analyzed (Table 5). 


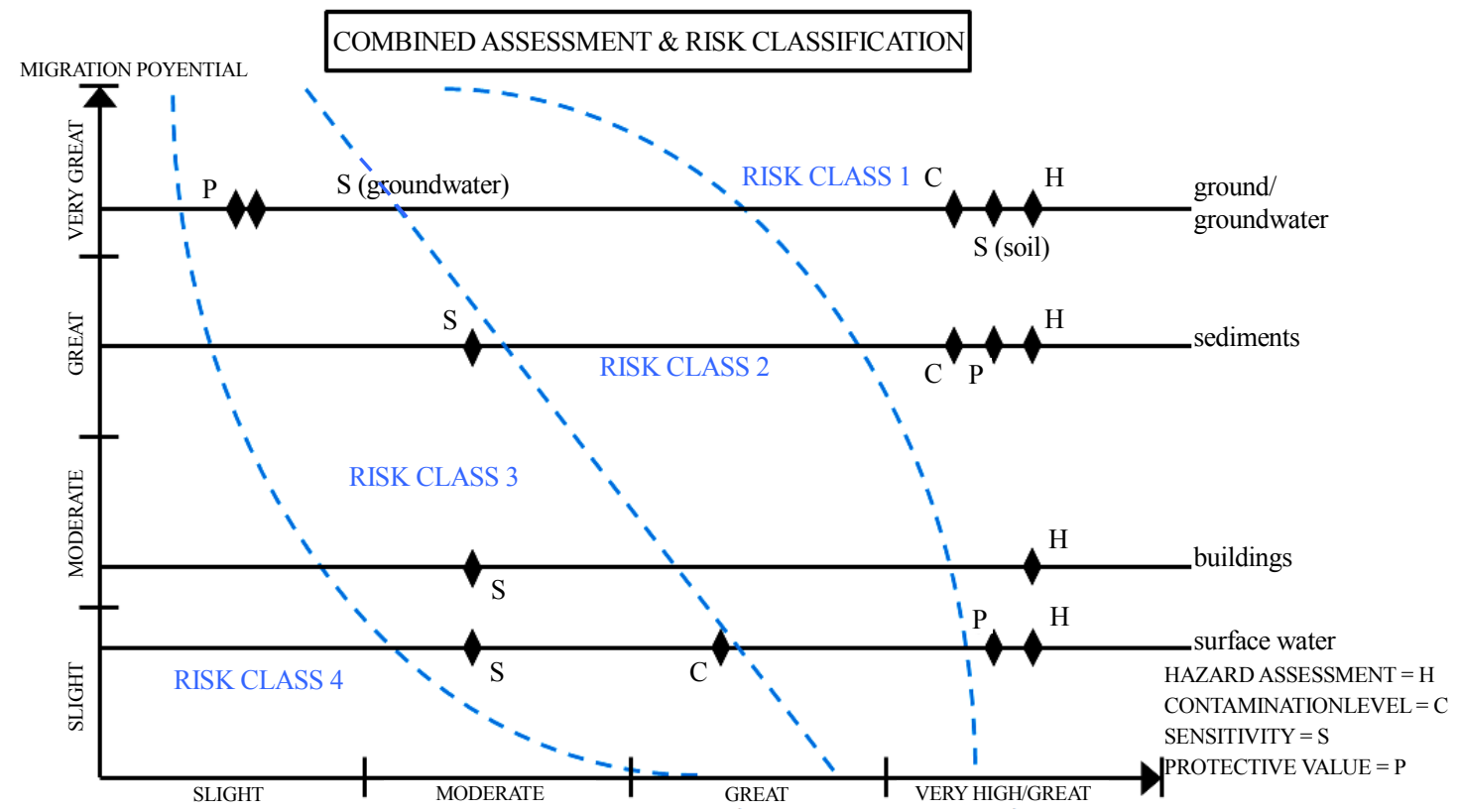

Figure 1. Example of a risk classification schematic diagram used in the comprehensive assessment in the Swedish MICS (SERA, 2002).

Table 3. MICS risk rankings and classes.

\begin{tabular}{|c|c|c|c|c|c|c|}
\hline Sites ID & Hazard & Contamination & Migrat. & Sensit. & Protection value & Final classes \\
\hline 1 & Very high & Very high & Very high & High & High & 1 \\
\hline 2 & High & Moderate & High & Moderate & Moderate & 3 \\
\hline 3 & Very high & High & Moderate & High & High & 2 \\
\hline 4 & Very high & High & High & Moderate & High & 2 \\
\hline 5 & Very high & High & High & Moderate & High & 2 \\
\hline 6 & Very high & Very high & High & High & High & 1 \\
\hline 7 & Very high & Moderate & Moderate & Moderate & High & 3 \\
\hline 8 & Low & Moderate & Moderate & Low & High & 3 \\
\hline 9 & Very high & High & High & Moderate & High & 2 \\
\hline 10 & Very high & High & High & Moderate & High & 2 \\
\hline 11 & Very high & High & High & Moderate & High & 2 \\
\hline 12 & Very high & High & High & Moderate & Moderate & 3 \\
\hline 13 & High & High & High & High & Moderate & 2 \\
\hline 14 & Very high & High & Moderate & High & Moderate & 3 \\
\hline 15 & High & Low & Low & High & High & 3 \\
\hline 16 & High & Moderate & Low & High & High & 3 \\
\hline 17 & Very high & Moderate & Low & Low & Moderate & 4 \\
\hline 18 & High & Low & Moderate & Moderate & Low & 4 \\
\hline 19 & Very high & High & High & High & High & 2 \\
\hline 20 & High & Moderate & Moderate & Moderate & Moderate & 3 \\
\hline
\end{tabular}


Table 4. RSS risk rankings and site scores.

\begin{tabular}{|c|c|c|c|c|c|}
\hline Sites ID & SW pathway & GW pathway & Soil contact & Highest pathway scores & Site scores \\
\hline 1 & High & High & Medium & High & High \\
\hline 2 & Low & Low & Medium & Medium & Medium \\
\hline 3 & Medium & Medium & Medium & Medium & Medium \\
\hline 4 & Medium & Medium & Medium & Medium & Medium \\
\hline 5 & Medium & Low & Medium & Medium & Medium \\
\hline 6 & High & High & High & High & High \\
\hline 7 & Medium & Medium & Medium & Medium & Medium \\
\hline 8 & Low & Low & Low & Low & Low \\
\hline 9 & Medium & Medium & Medium & Medium & Medium \\
\hline 10 & Medium & Medium & Medium & Medium & Medium \\
\hline 12 & Medium & Medium & Medium & Medium & Medium \\
\hline 13 & Low & Medium & Medium & Medium & Medium \\
\hline 14 & Medium & Medium & Medium & Medium & Medium \\
\hline 15 & Low & Low & Medium & Medium & Medium \\
\hline 16 & Low & Low & Medium & Medium & Medium \\
\hline 17 & Low & Low & Low & Low & Low \\
\hline 18 & Low & Low & Low & Low & Low \\
\hline 19 & Medium & High & Medium & High & High \\
\hline 20 & Medium & Low & Low & Medium & Medium \\
\hline
\end{tabular}

Table 5. Comparison of different methods.

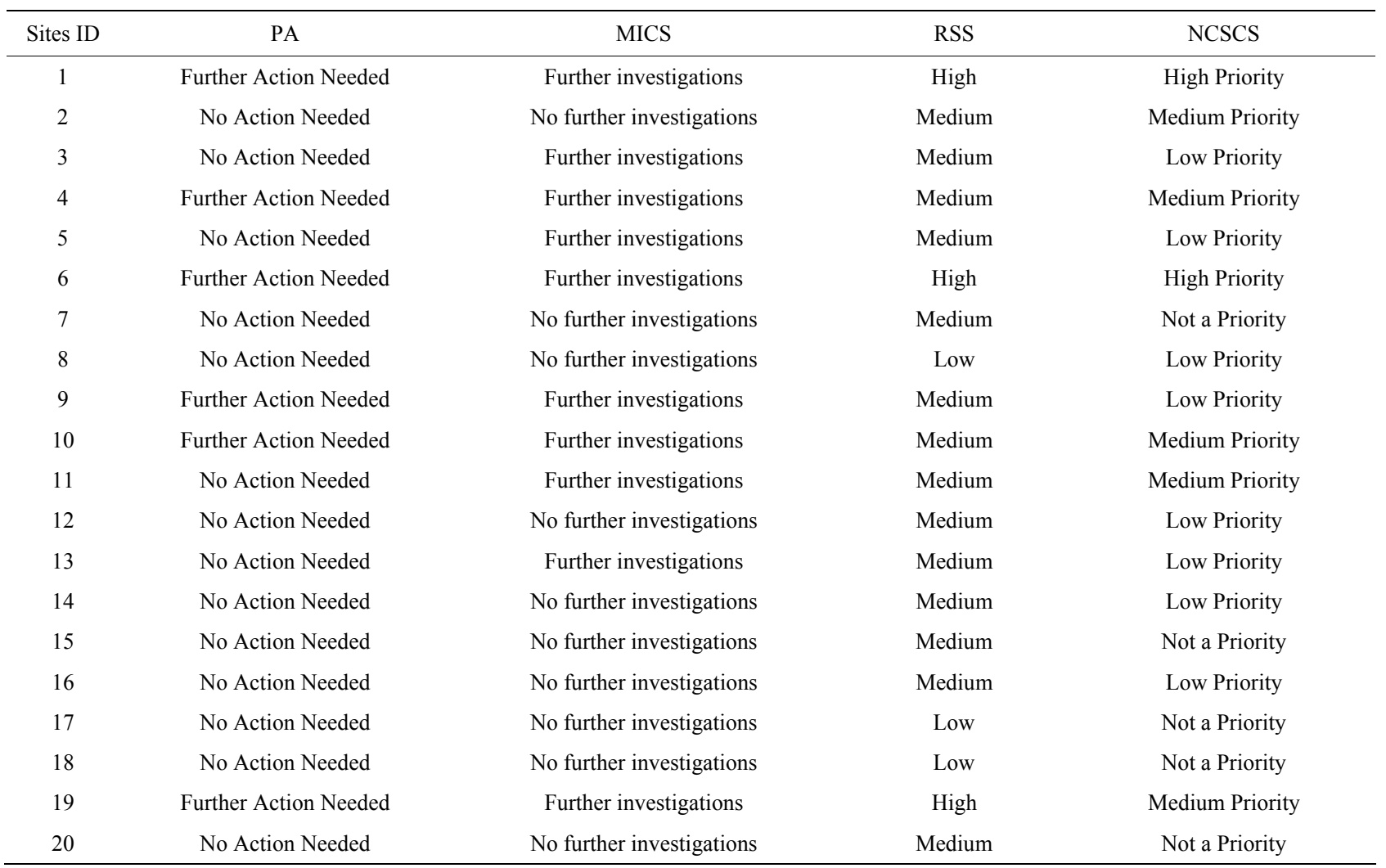




\subsection{Statistical Analysis}

The results of PA, MICS and RSS were compared with the results of NCSCS and PQRA by using Spearman rank correlations. A significance value equal or less than $0.05(\leq 0.05)$ is taken as the threshold of acceptable correlation between two variables (the number of data pairs are 20 , and the correlation is greater than 0.44 ), which means a chance that the strength of the relationship (the $\rho$ coefficient) happened by chance if the null hypothesis were true is less that $5 \%$ [12-14].

\section{Results and Discussions}

\subsection{Comparison between the Four Risk Ranking Systems}

According to the assessment results of PA method, there are six sites eligible for further actions: They are site 1, 4, $6,9,10,19$. The six sites are all among MICS Class 1 and Class 2 categories to receive the "further investigation needed" recommendations. The six sites are all among RSS's high and medium risk categories. Five out of six sites (except for site 9) are among the medium priority and high priority sites using the NCSCS system.

According to the MICS assessment, there are ten sites among Class 1 and Class 2 risk categories, which are slated for further investigation. These include sites $1,3,4$, $5,6,9,10,11,13$ and 19. Six out of ten sites are among the "action needed" sites according to the PA system, with the exception of sites $3,5,11,13$; the ten sites are all among the high or medium risk categories according to RSS method; and seven out of ten sites are among the medium priority and high priority sites categories according to NCSCS system, with the exception of site 3, 9 and 13 .

According to the RSS system, there are three sites (site $1,6,19)$ that are at the high risk levels. These sites are all among those that are eligible for "further action" according to PA, MICS, and NCSCS systems. There are three sites at the low risk levels, they are site 8,17 and 18 . The three low risk sites are all among those that "no further action needed" category according to PA, MICS, and NCSCS. Majority of the sites (14 out of 20) are among the RSS medium risk level category.

From the results of comparison we can see that US's PA method, Sweden's MICS method and Canada's NCSCS method all provide similar recommendations for further actions. While New Zealand's RSS method can only distinguish those sites with very high risk levels and very low risk levels, the majority of the sites fall in the medium risk category. The characteristics of each system and how they impact the results are further discussed below.

\subsubsection{PA System}

The PA method emphasizes more on surface water pathway, primary fishery targets and primary sensitive environment targets than other exposure pathways targets [15]. The six sites which are among the PA's "further action recommendations" category, all have either surface water primary fishery targets, surface water primary sensitive environment targets, or have both.

In PA system, primary targets get much higher scores than secondary targets. If people and resources are suspected to be threatened by a release from the site, which means there are primary targets on site, all factors will be given much higher values then they are not. This is different from the MICS and RSS systems. For example, site 1 gets higher PA score than site 6 as the wet land on site 1 is a primary target, while the wet land on site 6 is a secondary target, although site 6 is more sensitive land use than site 1 . There are surface water fishery activities within the target distance limits on sites $3,5,8$ and 11 as well, but they are secondary fishery targets, so these sites cannot get scores high enough to be among the PA "further action needed" category.

The number of people present within target distance limits is the basis of PA assessment. This is another reason why only 6 out of 20 contaminated sites with surface water primary fishery and sensitive environment targets fall in the PA "further action needed" category. According to the sites conditions, 13 out of 20 sites are neither residential nor commercial areas. Even of the 5 commercial and 2 residential areas, there are limited number people on sites. In summary, there are limited numbers of people on all the twenty sites, which leads to low PA scores.

\subsubsection{MICS System}

More attention is paid to hazard level and contaminant level in the MICS assessment process. This is the reason why sites 3, 5, 11 and 13 are among the MICS "action needed" category, but not according to PA method. There are relatively high hazard levels and contamination levels on these four sites. As a precondition for using the PA system is eligibility for CERCLA response, hazard levels are not considered by PA assessment, and so the PA assessment results are not affected by hazard levels.

The MICS assessment results are qualitative risk classes, more professional judgment is needed in MICS overall assessment using the schematic diagram compared to the other methods. This has both its strength and weakness. The strength is it gives the assessor more flexibility to consider site specific conditions which are not specified in the criteria. The weakness is that it can cause inconsistencies among different assessors. Sites 2, 5, 7, 11, 12 and 20 all show up as scattered points on the assessment diagrams, and professional judgment is applied to their MICS assessments. Oberg [15] mentioned that MICS is a qualitative method and hazard level plays important role 
in the assessment process.

Human health risk is evaluated at the individual level in the MICS system. The site will be sensitive even with one resident on site. It means that the risk of a site is assumed to be the same regardless of the number of people present onsite. This is different from the PA method. This point is illustrated by site 3 (one resident on site), which as per MICS has the category "further investigation needed", but not according to PA.

\subsubsection{RSS System}

RSS is a coarse risk ranking system and results in only three risk classes. It can distinguish the very high and very low risks sites, but cannot provide fine distinction between sites of similar risk. As such most sites fall in the medium risk category. According to RSS assessment results, there are three high risk sites, three low risk sites and majority of the sites (14 out of 20 ) in the medium risk category.

There is no specific factor representing sensitive environment in RSS system, the presence of sensitive environment feature does not affect the RSS assessment result. For example, site 10 has a wetland 900 meter north east of the site, which is suspected to be contaminated, the PA and MICS assessment results are both at high risk levels, while the RSS result is still among the medium risk category.

\subsection{Results of Statistical Analysis}

Table 6 provides the Spearman rank correlation matrices between the results of PA, MICS, RSS, NCSCS and PQRA. The values in brackets give the significance level. Correlation coefficient $\rho$ expressed in bold and italic face are statistically significant.

From Table 6 we can see that there are acceptable correlations among the four risk ranking systems (PA, MICS, RSS and NCSCS), this serves the basis that the four risk ranking systems could be able to achieve the similar outcomes regarding further action recommendations.

Regarding the correlations among the three systems (PA, MICS and RSS) being evaluated and the PQRA which is chosen as the screening level risk assessment protocol, there are following results as showed in Table 6:

PA scores are correlated with only three out of eight PQRA components: plants \& invertebrates, soil microbes, aquatic life with the exception of the other five components. The lack of acceptable correlations between PA and PQRA is due to the hazard quotient of PQRA is the measurement of hazard posed by each contaminant, to each receptor, via each exposure route that was expressed as a dimensionless hazard quotient. Hazard quotient is the measured or predicted dose divided by the tolerable

Table 6. PA, MICS, RSS, NCSCS and PQRA.

\begin{tabular}{|c|c|c|c|c|c|c|c|c|c|c|c|c|}
\hline$\rho$ & PA & MICS & RSS & NCSCS & $\begin{array}{l}\text { Hum. } \\
\text { (PQRA) }\end{array}$ & $\begin{array}{c}\text { Plant } \\
\text { (PQRA) }\end{array}$ & $\begin{array}{l}\text { Micro. } \\
\text { (PQRA) }\end{array}$ & $\begin{array}{c}\text { Cow } \\
\text { (PQRA) }\end{array}$ & $\begin{array}{c}\text { Vole } \\
\text { (PQRA) }\end{array}$ & $\begin{array}{c}\text { Shrew } \\
\text { (PQRA) }\end{array}$ & $\begin{array}{l}\text { Kestr. } \\
\text { (PQRA) }\end{array}$ & $\begin{array}{l}\text { Aqua. } \\
\text { (PQRA) }\end{array}$ \\
\hline PA & 1.0 & & & & & & & & & & & \\
\hline MICS & $\begin{array}{c}-0.87 \\
(0.000)\end{array}$ & 1.0 & & & & & & & & & & \\
\hline RSS & $\begin{array}{c}-0.59 \\
(0.006)\end{array}$ & $\begin{array}{c}0.75 \\
(0.000)\end{array}$ & 1.0 & & & & & & & & & \\
\hline NCSCS & $\begin{array}{c}0.62 \\
(0.004)\end{array}$ & $\begin{array}{c}-0.77 \\
(0.000)\end{array}$ & $\begin{array}{c}-0.68 \\
(0.001)\end{array}$ & 1.0 & & & & & & & & \\
\hline $\begin{array}{c}\text { HUM. } \\
\text { (PQRA) }\end{array}$ & $\begin{array}{c}0.27 \\
(0.243)\end{array}$ & $\begin{array}{c}-0.59 \\
(0.006)\end{array}$ & $\begin{array}{l}-0.60 \\
(0.005)\end{array}$ & $\begin{array}{c}0.63 \\
(0.003)\end{array}$ & 1.0 & & & & & & & \\
\hline $\begin{array}{l}\text { PLANT } \\
\text { (PQRA) }\end{array}$ & $\begin{array}{c}0.53 \\
(\mathbf{0 . 0 1 7})\end{array}$ & $\begin{array}{c}-0.56 \\
(0.010)\end{array}$ & $\begin{array}{c}-0.35 \\
(0.131)\end{array}$ & $\begin{array}{c}0.31 \\
(0.187)\end{array}$ & $\begin{array}{c}0.27 \\
(0.250)\end{array}$ & 1.0 & & & & & & \\
\hline $\begin{array}{l}\text { MICRO. } \\
\text { (PQRA) }\end{array}$ & $\begin{array}{c}0.62 \\
(0.004)\end{array}$ & $\begin{array}{c}-0.65 \\
(0.002)\end{array}$ & $\begin{array}{c}-0.47 \\
(0.037)\end{array}$ & $\begin{array}{c}0.65 \\
(0.002)\end{array}$ & $\begin{array}{c}0.49 \\
(0.027)\end{array}$ & $\begin{array}{c}0.33 \\
(0.151)\end{array}$ & 1.0 & & & & & \\
\hline $\begin{array}{c}\text { COW } \\
\text { (PQRA) }\end{array}$ & $\begin{array}{c}-0.33 \\
(0.891)\end{array}$ & $\begin{array}{c}-0.17 \\
(0.464)\end{array}$ & $\begin{array}{l}-0.39 \\
(0.089)\end{array}$ & $\begin{array}{c}0.25 \\
(0.285)\end{array}$ & $\begin{array}{c}0.60 \\
(0.005)\end{array}$ & $\begin{array}{c}0.26 \\
(0.261)\end{array}$ & $\begin{array}{c}0.08 \\
(0.752)\end{array}$ & 1.0 & & & & \\
\hline $\begin{array}{c}\text { VOLE } \\
\text { (PQRA) }\end{array}$ & $\begin{array}{c}0.33 \\
(0.162)\end{array}$ & $\begin{array}{c}-0.52 \\
(0.019)\end{array}$ & $\begin{array}{c}-0.65 \\
(0.002)\end{array}$ & $\begin{array}{c}0.47 \\
(\mathbf{0 . 0 3 5})\end{array}$ & $\begin{array}{c}0.49 \\
(0.028)\end{array}$ & $\begin{array}{c}0.56 \\
(0.010)\end{array}$ & $\begin{array}{c}0.50 \\
(0.026)\end{array}$ & $\begin{array}{c}0.48 \\
(0.034)\end{array}$ & 1.0 & & & \\
\hline $\begin{array}{l}\text { SHREW } \\
\text { (PQRA) }\end{array}$ & $\begin{array}{c}0.32 \\
(0.172)\end{array}$ & $\begin{array}{c}-0.54 \\
(0.015)\end{array}$ & $\begin{array}{c}-0.63 \\
(0.003)\end{array}$ & $\begin{array}{c}0.50 \\
(0.026)\end{array}$ & $\begin{array}{c}0.52 \\
(0.019)\end{array}$ & $\begin{array}{c}0.54 \\
(0.013)\end{array}$ & $\begin{array}{c}0.48 \\
(0.033)\end{array}$ & $\begin{array}{c}0.45 \\
(0.045)\end{array}$ & $\begin{array}{c}0.99 \\
(0.000)\end{array}$ & 1.0 & & \\
\hline $\begin{array}{l}\text { KESTR. } \\
\text { (PQRA) }\end{array}$ & $\begin{array}{c}0.42 \\
(0.069)\end{array}$ & $\begin{array}{c}-0.59 \\
(0.007)\end{array}$ & $\begin{array}{l}-0.62 \\
(0.004)\end{array}$ & $\begin{array}{c}0.56 \\
(0.011)\end{array}$ & $\begin{array}{c}0.68 \\
(0.001)\end{array}$ & $\begin{array}{c}0.50 \\
(\mathbf{0 . 0 2 5})\end{array}$ & $\begin{array}{c}0.68 \\
(0.001)\end{array}$ & $\begin{array}{c}0.50 \\
(0.025)\end{array}$ & $\begin{array}{c}0.84 \\
(0.000)\end{array}$ & $\begin{array}{c}0.85 \\
(0.000)\end{array}$ & 1.0 & \\
\hline $\begin{array}{l}\text { AQUA. } \\
\text { (PQRA) }\end{array}$ & $\begin{array}{c}0.81 \\
(\mathbf{0 . 0 0 0})\end{array}$ & $\begin{array}{c}-0.86 \\
(0.000)\end{array}$ & $\begin{array}{c}-0.51 \\
(0.023)\end{array}$ & $\begin{array}{c}0.79 \\
(0.000)\end{array}$ & $\begin{array}{c}0.50 \\
(0.027)\end{array}$ & $\begin{array}{c}0.51 \\
(\mathbf{0 . 0 2 3})\end{array}$ & $\begin{array}{c}0.78 \\
(\mathbf{0 . 0 0 0})\end{array}$ & $\begin{array}{l}0.021 \\
(0.93)\end{array}$ & $\begin{array}{c}0.53 \\
(\mathbf{0 . 0 1 6})\end{array}$ & $\begin{array}{c}0.55 \\
(0.012)\end{array}$ & $\begin{array}{c}0.65 \\
(0.002)\end{array}$ & 1.0 \\
\hline
\end{tabular}


dose. As mentioned earlier, due to CERCLA response eligibility, hazard level is not considered by PA assessment.

MICS risk rankings are correlated with 7 out of 8 PQRA components with the exception of cow. There are pretty good correlations between MICS and PQRA methods. This can be explained by one of the MICS emphasized points, which is hazard level plays important roles in MICS assessment.

RSS risk rankings are correlated with 6 out of 8 PQRA components with the exception of cow, plants \& invertebrates.

\section{Conclusions}

Based on the results of this research, the following conclusions can be made:

1) The PA, MICS and NCSCS can achieve similar conclusions regarding further actions, though they are not in complete agreement. RSS can distinguish very high level and very low level risk sites, the majority of the sites fall in the RSS medium risk category.

2) Acceptable correlations exist between the results of PA, MICS, RSS, NCSCS and PQRA, with the exception of the correlation between PA and PQRA.

\section{REFERENCES}

[1] Canadian Council of Ministers of Environment (CCME), "Guidance Document on the Management of Contaminated Sites in Canada," 1997.

http://www.ccme.ca/assets/pdf/pn_1279_e.pdf

[2] G. Prokop, M. Schamann and I. Edelgaard, "Management of Contaminated Sites inWestern Europe," European Environment Agency, 2000.

http://www.eea.europa.eu/publications/Topic_report_No_ 131999

[3] R. J. Thiessen and G. Achari, "A Comparison of 2008 National Classification System for Contaminated Sites scores to Preliminary Quantitative Risk Assessment Hazard Quotients," Canadian Journal of Civil Engineering, Vol. 38, No. 7, 2011, pp. 719-728.

[4] United States Environmental Protection Agency (US EPA), "Guidance for Performing Preliminary Assessments under CERCLA," 1991.

http://www.epa.gov/superfund/sites/npl/hrsres/pa/paguida nce.pdf
[5] Swedish Environmental Protection Agency (SERA) "Methods for Inventories of Contaminated Sites," Environmental Quality Criteria and Guidance for Data Collection, 2002.

http://www.naturvardsverket.se/Documents/publikationer /620-5053-2.pdf

[6] Ministry for the Environment New Zealand (MENZ), "Risk Screening System," Contaminated Land Management Guidelines No. 3, Wellington, 2004.

http://www.mfe.govt.nz/publications/hazardous/contamin ated-land-mgmt-guidelines-no3/contaminated-land-mgmt -guidelines-no3.pdf

[7] Canadian Council of Ministers of the Environment (CCME), "National Classification System for Contaminated Sites: Guidance Document," Canadian Council of Ministers of the Environment, Winnipeg, 2008.

http://www.ccme.ca/assets/pdf/pn_1403_ncscs_guidance e.pdf

[8] R. J. Thiessen, "An Evaluation of the 2008 National Classification System for Contaminated Sites," M.Sc. Thesis, University of Calgary, Calgary, 2010.

[9] Health Canada, "Federal Contaminated Site Risk Assessment in Canada, Part I: Guidance on Human Health Preliminary Quantitative Risk Assessment (PQRA)," 2004. http://www.hc-sc.gc.ca/ewh-semt/pubs/contamsite/part-pa rtie_i/index-eng.php

[10] Canadian Council of Ministers of Environment (CCME), "A Framework for Ecological Risk Assessment: General Guidance," 1996. http://www.ccme.ca/assets/pdf/pn_1195_e.pdf

[11] Treasury Board of Canada Secretariat (TBCS), "Federal Contaminated Sites Inventory," 2010. http://www.tbs-sct.gc.ca/fcsi-rscf/home-accueil-eng.aspx

[12] J. H. Zar, "Significance Testing of the Spearman Rank Correlation Coefficient," Journal of American Statistical Association, Vol. 67, No. 339, 1972, pp. 578-580.

[13] C. Spearman, "The Proof and Measurement of Association between Two Things," International Journal of Epidemiology, Vol. 39, No. 5, 2010, pp. 1137-1150. doi:10.1093/ije/dyq191

[14] Wolfram Math World, "Spearman Rank Correlation Coefficient," 2013.

http://mathworld.wolfram.com/SpearmanRankCorrelation Coefficient.html

[15] K. B. T. Oberg, "Initial Screening of Contaminated Land: A Comparison of US and Swedish Methods," Environ Manage, Vol. 39, No. 3, 2007, pp. 226-234. 